\title{
PASSIVE COOLING OF THE PBMR SPENT AND USED FUEL TANKS
}

\author{
Wim F. Fuls \\ IST Nuclear, a division of IST Holdings, South Africa \\ PO Box 95355, Waterkloof, 0145, South Africa \\ Telephone no.: +27124267382, Fax : +27123482600 \\ E-mail :wim@ist.co.za
}

\begin{abstract}
The PBMR is a new generation high temperature gas cooled reactor, making use of spherical fuel elements. The spent fuel and partially burnt fuel (called used fuel) is stored in large storage tanks. This paper presents the cooling design of the storage tanks, with special emphasis on its passive cooling ability.

For corrosion protection, the tanks are cooled with a closed loop active system, however, passive cooling is seen as the ultimate cooling mode for the storage tanks. If the active cooling fails, the flow automatically bypasses the active system and passive cooling takes over. The active cooling is thus not safety-related; rather its purpose is for investment protection.

The storage tank design with its longitudinal internal cooling pipes has a good passive cooling ability. The layout of the tank concrete cubicle ensures that cooling air can flow only in the desired direction. CFD analyses have been done for various heat load scenarios inside the tank. Passive cooling exists for tanks with a low spent fuel fill level with heat load below $25 \mathrm{~kW}$ up to a tank containing a full PBMR core (used fuel) with heat load of $640 \mathrm{~kW}$. For all scenarios, the maximum fuel temperature was below $400^{\circ} \mathrm{C}$.

A method was developed to calculate the transient passive cooling characteristics of the tank at a fraction of the time it takes CFD by using the pipe network simulation software Flownex. The method showed flow phenomenon similar to what CFD analyses have shown, but also new phenomenon which have not been investigated with CFD yet.
\end{abstract}

A two dimensional representation of the storage tank and cubicle layout have been built. This experiment demonstrates the passive cooling ability of the tank. It also proves the flow characteristics that were predicted by the CFD and Flownex analyses.

It has been shown through diverse techniques that the fuel inside the tanks can be cooled passively. There are still a few aspects which need to be explored in more detail, but overall it can be said that passive cooling of the PBMR spent and used fuel in bulk storage tanks is viable.

Keywords: Passive Cooling; Spent Fuel; PBMR; Chimney Effect; Passive Fallback 


\section{INTRODUCTION}

The PBMR is a new generation graphite moderated, high temperature, gas-cooled reactor being designed in South Africa. It makes use of spherical fuel elements and a continuous fuelling scheme. IST Nuclear was contracted by PBMR (Pty) Ltd. to design and supply the Fuel Handling and Storage System (FHSS) of the reactor. A primary task of the FHSS is the nuclear safe storage of all radioactive fuel that is discharged from the reactor.

PBMR (Pty) Ltd. has opted for dry bulk storage of all irradiated fuel spheres (including spent fuel and partially burnt fuel). This places the design outside any traditional storage system currently employed in the world, as all of them make use of relatively small movable containers. The cooling design was therefore tailored for dry bulk storage tanks. This paper presents the proposed solution for the decay heat removal function of the FHSS.

\section{DESIGN PHILOSOPHY}

A primary philosophy employed in the PBMR design as a whole is that it should be inherently safe, taking no credit for active systems, including all redundant and stand-by systems. This philosophy is also applicable for the cooling design of the spent fuel and used fuel tanks. The focus of the design was therefore on passive decay heat removal under any condition (normal and abnormal). This does not exclude the use of active systems that may be needed for prevention of corrosion of the tank, or to prevent the air being exposed to uncontrolled ionizing radiation under normal circumstances. However, no credit will be taken for the active system in safety analyses.

Another primary design driver for the PBMR is overall life cycle cost optimization. This can be divided into two major parts, namely initial capital cost, and operating cost. To reduce the initial capital cost of the cooling design, one needs to minimize the initial installed cooling capacity of the system, and be able to expand the capacity as needed. Secondly, to reduce the operating cost one minimizes the amount of active components, replacement parts and maintenance activities.

\section{COOLING DESIGN AND LAYOUT}

\subsection{Storage Tank}

The PBMR has twelve storage tanks, capable of storing a total of more than six million spheres. The spheres can be either spent fuel (fuel which has reached its target burn-up); used fuel (an average burn-up sphere from an equilibrium core during core maintenance); or graphite spheres (used during the reactor start-up and re-fuelling after core maintenance). All storage tanks have the same design, although a distinction is made between a Spent Fuel Tank (SFT), a Used Fuel Tank (UFT) and a Graphite Tank (GRT). This distinction describes the predefined contents of the tank, although the contents can be stored in any tank. The cooling design is thus the same for all tanks, and will be tailored during operation depending upon the type of heat load inside the tank. This aspect will become clearer in the later sections of this paper.

A storage tank is a large cylindrical pressure vessel, $18 \mathrm{~m}$ high with a $3.1 \mathrm{~m}$ inner diameter. It is made from thinwalled carbon steel, capable of sustaining $1 \mathrm{MPa}$ internal pressure. Inside the tank are a number of cooling tubes running from the bottom to the top. The fuel spheres are stored in a helium environment at atmospheric pressure. The decay heat is transferred from sphere to sphere to the tank surfaces, and then via convection to the air on the outside. No heat is actively removed from inside the tank.

\subsection{Tank Cubicle Layout and Airflow}

Each storage tank is located in its own concrete cubicle (see Figure 1). The cubicle is split into an upper and lower cavity at the level of the tank support. At the upper cavity is the gamma shield, which extends from the tank support upward to the upper floor. This shield allows human access to the upper cavity, even when the tank contains fuel, and also separates the inlet from the outlet airflow. There are two rectangular air inlets and one central outlet at the upper floor.

A thermal shield is located at an offset around the tank extending from the ring support down to the bottom. This shield prevents thermal radiation from the tank to the surrounding concrete structures, and also directs the cooling air downwards from the top of the cavity and upwards along the tank. 
At the bottom of the tank cubicle, the cooling air splits up into the cooling tubes inside the tank and the gap between the tank and the thermal shield. All decay heat is absorbed by the cooling air as it flows upward along the tank. The flow collects above the tank, moves past the horizontal part of the gamma shield and exits at the central outlet in the upper floor.

Above the upper floor, connected to the inlets and outlets are two Cooling and Conditioning Units (CCU). These units perform all the tank cooling and air conditioning functions. The units can be configured to operate in different cooling modes, depending upon the heat load inside the tank.

The tubes inside the tank, along with the gap between the thermal shield and the tank act as vertical heated chimneys. As a result, the storage tank has a strong passive cooling ability. The flow path as described above and depicted in Figure 1 will exist for active and passive cooling, and for all heat loads that could exist inside the tank.

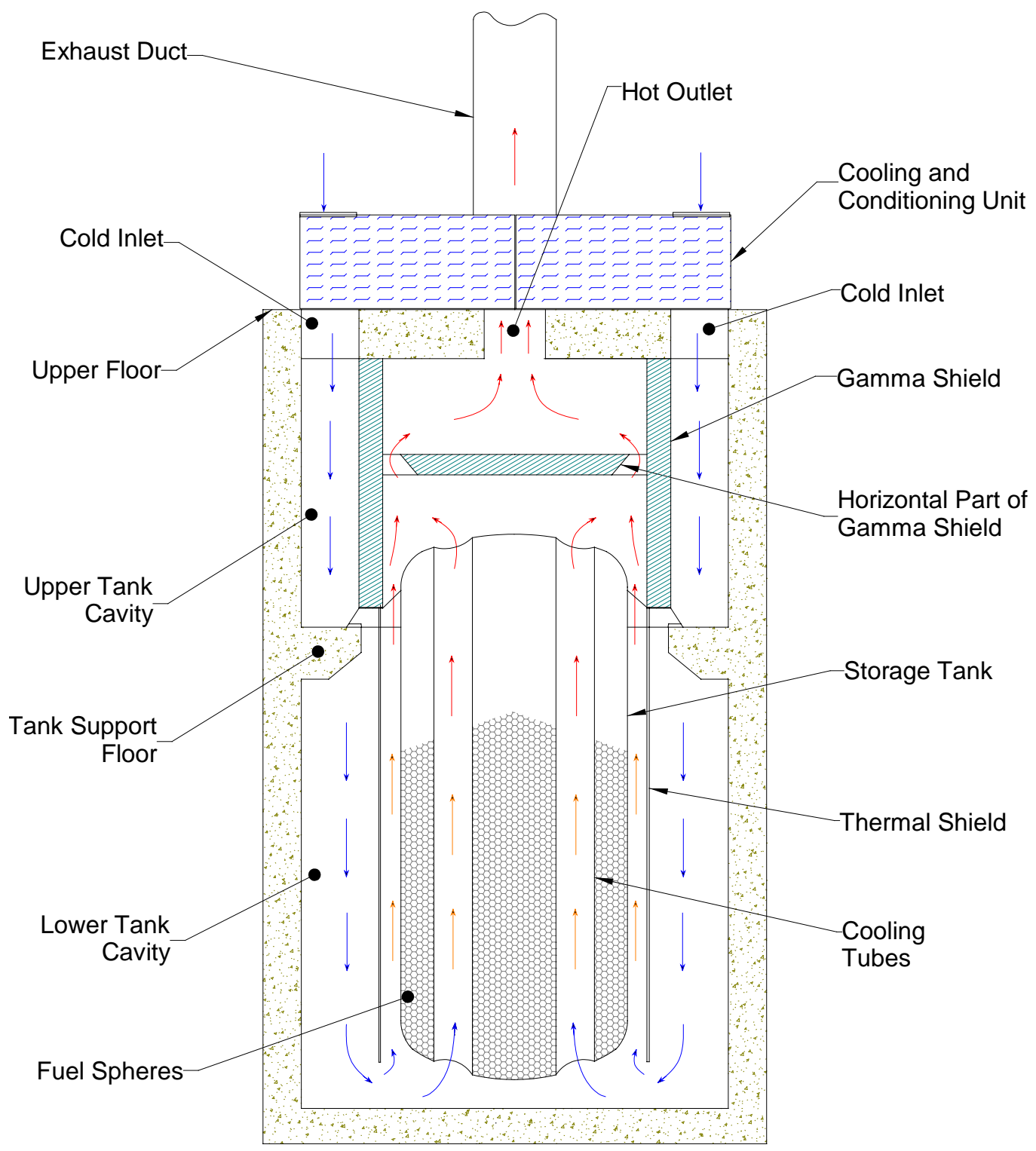

Figure 1. Layout of the storage tank in its concrete cubicle. 


\subsection{Cooling Modes}
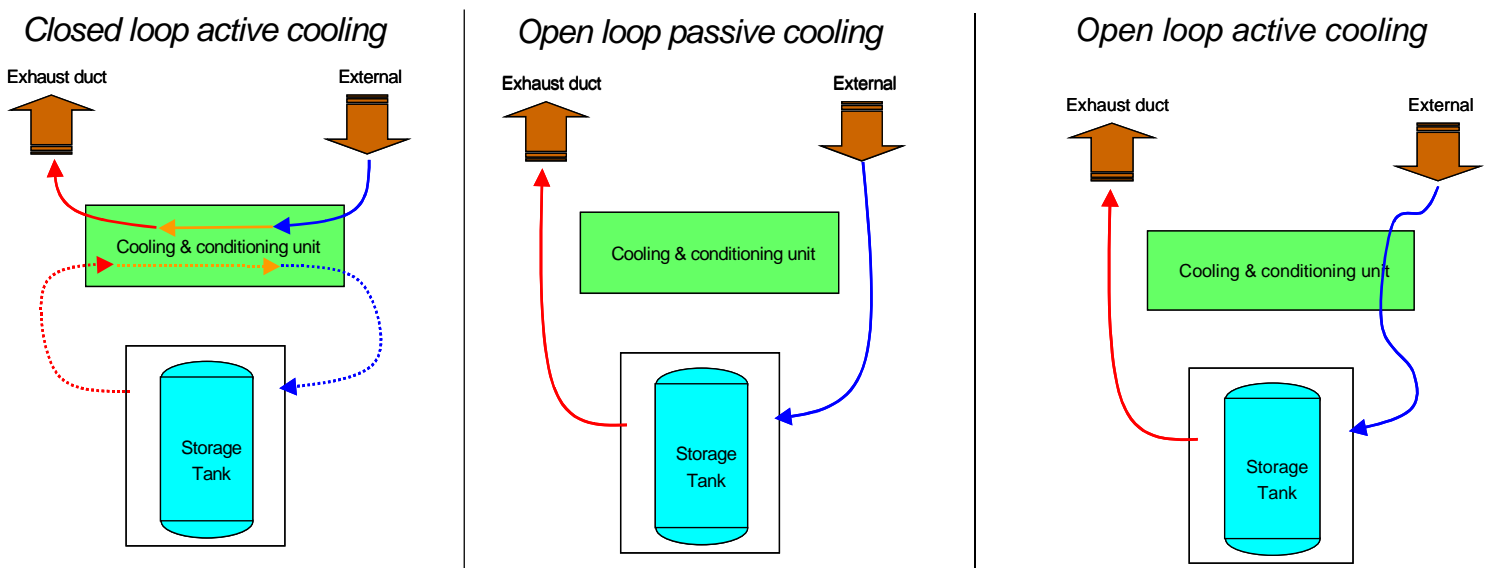

Figure 2. Cooling modes of the storage tank.

The storage tanks can be cooled in three different modes as shown in Figure 2. The primary cooling mode is Closed Loop Active Cooling. In this mode the cooling air is circulated in a closed loop around the tank cubicle. The two CCUs condition the closed loop air to a purity level such as to prevent any significant corrosion on the tank. The heat is transferred from the internal loop to the atmosphere via an air-to-air heat exchanger.

If the active cooling fails for some reason, louvres will automatically fall open to allow air from outside to directly enter the tank cubicle and exit at the exhaust duct, bypassing the heat exchanger and filters. Heat removal is then achieved in an Open Loop Passive Cooling mode. This mode can be sustained indefinitely, but to protect the tank from excessive corrosion, the Closed Loop Active Cooling should be restored as soon as possible.

In very rare instances, such as during a core maintenance operation, the storage tank may contain a heat load higher than the capacity of the heat exchangers. In such a case, the tank is cooled in an Open Loop Active Cooling mode, whereby filtered air is passed through the tank cubicle in a once-through process. Some corrosion may occur, but since this mode is only required for about three months, it is felt to be non-significant. Again, if the active cooling fails, louvres will automatically open to allow passive cooling to take over.

Passive cooling is therefore the ultimate decay heat removal mechanism, while active cooling is only employed to protect the tanks from excessive corrosion. Additionally, the active cooling limits the amount of organisms in the air-stream that is exposed to the radiation from the tank.

\section{PROOF OF COOLING}

Star-CD, a Computational Fluid Dynamics (CFD) software is used to calculate the storage tank temperatures during active cooling. Results can be obtained for various forced mass flows, and can be compared with analytical calculations and other CFD software (such as Fluent). The challenge lies in the proof of passive cooling. This is because the flow is driven by buoyancy effects at very low pressure differences during passive cooling. The flow is often mathematically unstable and a number of valid flow scenarios may exist.

The question is: What are the actual flow characteristics one could expect, and specifically the total mass flow through the system. Once that is known, the temperatures can be deducted from results obtained through active cooling analyses. Other questions also arise, such as: Will the flow start in the correct direction if it was halted, for example, after a blocked outlet was opened? Can sufficient mass flow be generated during low fill levels inside the tank? What would the effect be of external pressure changes around the building?

To answer these questions, different types of analyses were performed. Also, a test demonstration model was built. The following paragraphs contain the details of the different analyses and the test. 


\subsection{CFD Analysis}

The goal is to limit the fuel temperatures below $350^{\circ} \mathrm{C}$ under normal conditions, although a limit of $400^{\circ} \mathrm{C}$ is set to prevent excessive graphite corrosion if oxygen does enter the tank during abnormal conditions. CFD analyses were thus performed to determine the minimum mass flow required to ensure the desired fuel temperatures.

The required mass flow is very dependant upon the heat load inside the tank. Four crucial heat load scenarios have been identified:

- A tank completely filled with spent fuel $(140 \mathrm{~kW})$. This represents the highest heat load for the closed loop active cooling.

- A tank completely filled with used fuel $(640 \mathrm{~kW})$. This represents the highest heat load for the open loop active cooling.

- A tank filled to only $5 \%$ capacity with spent fuel $(23 \mathrm{~kW})$. This is a very low heat load that may present difficulty during passive cooling.

- A tank filled at $25 \%$ level with used fuel $(220 \mathrm{~kW})$. This is the stage when the maximum fuel temperatures exist in the tank during loading because of the high decay heat density relative to the small exposed heat transfer surfaces of the tank.

The CFD analyses showed that a mass flow of about $2 \mathrm{~kg} / \mathrm{s}$ is needed for the closed loop active cooling, and about $7 \mathrm{~kg} / \mathrm{s}$ for the open loop active cooling. Similar mass flows are thus required for the respective open loop passive cooling modes.

In order to achieve a stable passive cooling CFD solution, one needs to define initial conditions that closely resemble the final passive cooling scenario. To find the closest initial condition, a number of active cooling analyses with different mass flows are performed, and the pressure differences between the inlet and outlet are noted. For passive cooling, both the inlet and outlet has to be at the same total pressure, thus the active cooling case with the smallest pressure difference is chosen as the initial condition.

It was found that the maximum fuel temperature during passive cooling was below $400^{\circ} \mathrm{C}$ for all four crucial heat load scenarios. The $640 \mathrm{~kW}$ case generates about $6 \mathrm{~kg} / \mathrm{s}$ mass flow, while the $23 \mathrm{~kW}$ case produces a mass flow of about $2.5 \mathrm{~kg} / \mathrm{s}$. These results are strong confirmations that it is possible to limit the fuel temperature to below $400^{\circ} \mathrm{C}$ during an abnormal event using passive cooling. However, the analyses assume a certain initial flow condition. To study the effect of different initial conditions, one needs to perform very time-consuming transient analyses, or use methods other than CFD.

\subsection{Flownex Analysis}

In order to have accurate heat transfer characteristics in the CFD model, the boundary cells had to be in the order of $10 \mathrm{~mm}$ thick. However, the overall size of the model is $25 \mathrm{~m}$, resulting in a CFD model with more than 700 000 cells, taking about one week of calculation on a powerful computer to converge. It is therefore not realistic to solve the passive flow for the full range of fill levels and various initial conditions. A faster method had to be developed.

The layout of the tank and the cubicle is such that there are well-defined flow paths from the inlet to the outlet. This allows one to approximate the tank and cubicle as a network of pipes and flow loss elements. The analyses were done using Flownex. It was also possible to include the fan characteristic curves and heat exchanger properties of the CCU.

The portions of significant flow loss (such as the ring support and gamma shield) are modeled using "User Defined" flow loss elements. The loss coefficients are determined from CFD analyses for various flow and temperature scenarios. The tank and thermal shield is simulated as a number of parallel pipes. The pipes are divided into a heated and an unheated part. A constant heat input is applied to the heated sections for steady state analyses, and a constant wall temperature for transient analyses.

The primary results obtained from the analyses are mass flows and gas temperatures in each pipe element. No information is calculated for the tank and fuel temperatures, however, this can be deduced from the active cooling analyses with similar mass flows. This is because from the tank's point of view, only the mass flow and temperatures per pipe is required to determine the temperatures of the fuel. 
By performing Flownex analyses, it was possible to investigate the effect of a sudden pressure increase at the chimney outlet, causing the flow to move in the opposite direction. Figure 3 shows the time history of the mass flows and temperature through the chimney and tank cooling pipes. The absolute value of the mass flow and temperatures are for this case of less importance, as it depends upon the actual heat load inside the tank. What is noteworthy is the direction and relative magnitude of the mass flow. The flow is defined positive in the direction showed in Figure 1, hence a negative mass flow will indicate reversed flow.
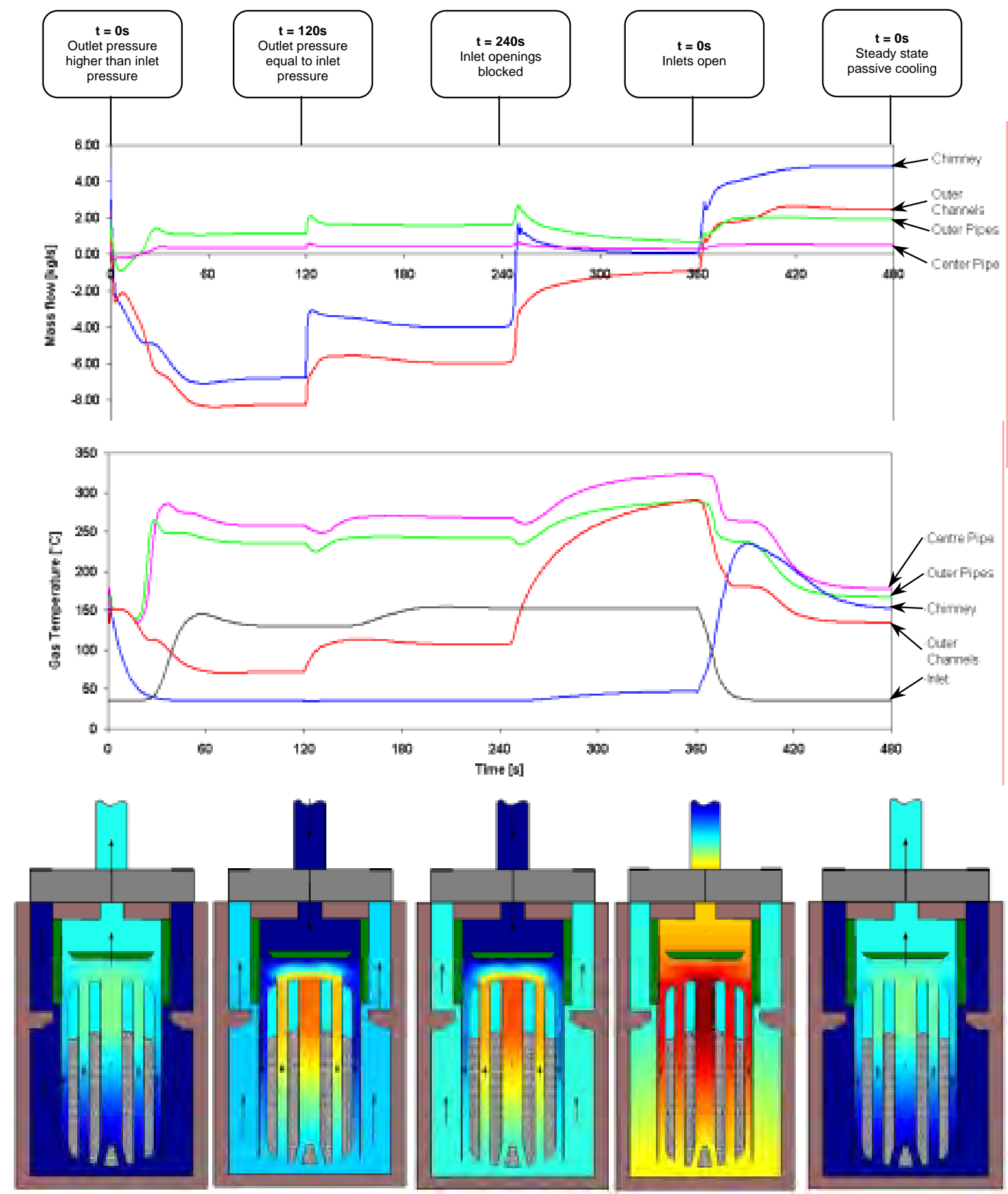

Figure 3. Transient results during passive cooling for the case where a reverse-flow is induced and then recovered by blocking the inlets. 
The pressure increase causes the flow in the chimney to reverse and reach an equilibrium state after about 60 seconds. In this state, an important phenomenon is seen: the flow in the centre tube and outer tubes are upward, while in the channels of the thermal shield it flows downward. There is thus a recirculation that occurs around the tank. This recirculation was also seen from a transient CFD analysis of a completely blocked system. The recirculation can be attributed to the strong chimney effect of the pipes.

After 120 seconds the outlet pressure was restored to the original pressure, equal to the inlet pressure. Again, within 60 seconds, a new equilibrium is reached, however, not the original passive cooling state. It seems that once a reverse equilibrium has been forced, the flow patterns will stay that way.

In order to return the flow to its original directions, the inlet openings are closed for 120 seconds. During this time, hot air starts to build up in the gamma shield volume and chimney. Recirculation around the tank still continues, but at much lower mass flows. When the openings are opened after the 120 seconds, there is enough buoyancy difference between the air in the gamma shield volume and the concrete cubicle so that the flow will start in the desired direction. The original passive cooling equilibrium is reached after 60 seconds.

The rate at which new equilibrium states are reached is very important. The fuel has a maximum temperature increase rate of about $25^{\circ} \mathrm{C} /$ hour $\left(0.42^{\circ} \mathrm{C} /\right.$ minute $)$. This rate is so slow, that within the 60 seconds it takes the air to stabilize, the tank wall temperatures do not change. The constant wall temperature assumption during transients is therefore quite valid.

\subsection{D Passive Cooling Demonstrator}

The ultimate proof of a cooling design is to build a representative test model. However, to build a dimensionally similar scale test of natural convection and buoyancy effects is virtually impossible due to the complex Grashof number. The test would need to be full scale with actual fuel spheres inside. The alternative is to build a small test which would present similar flow characteristics, but without any dimensional similarity.

A test setup was built that would demonstrate the principle functioning of the passive cooling. It was not intended to present any design information or validation of CFD analyses. The only prerequisite was that it should indicate the flow pattern correctly, and respond to transient conditions as expected for the storage tanks.

A two-dimensional representation of the tank and cubicle was made, representing a cross section through the tank and cooling pipes. Figure 4 shows a schematic drawing of the test layout. The fuel volume was represented by three rectangular heater elements $(40 \mathrm{~mm} \times 40 \mathrm{~mm}$ x $500 \mathrm{~mm}$ long) placed a distance from each other. This created two flow channels between the heaters, which would act in the same manner as the cooling tubes of the tank. The heater elements were heated along its full length, thus simulating a full tank. It was also possible to apply heat only at the bottom to simulate a tank at about $5 \%$ fill level.

A single "shield" running from the top to the bottom represented the gamma shield and thermal shield. The effect of the tank support is thus not included. This did not affect the results significantly. The horizontal part of the gamma shield was however present in the test model. It was possible to remove the horizontal part to see the effect on the flow.

An extension could be added to the outlet to simulate a chimney. The length, contraction ratio and exit geometry could be changed to indicate the effect. 


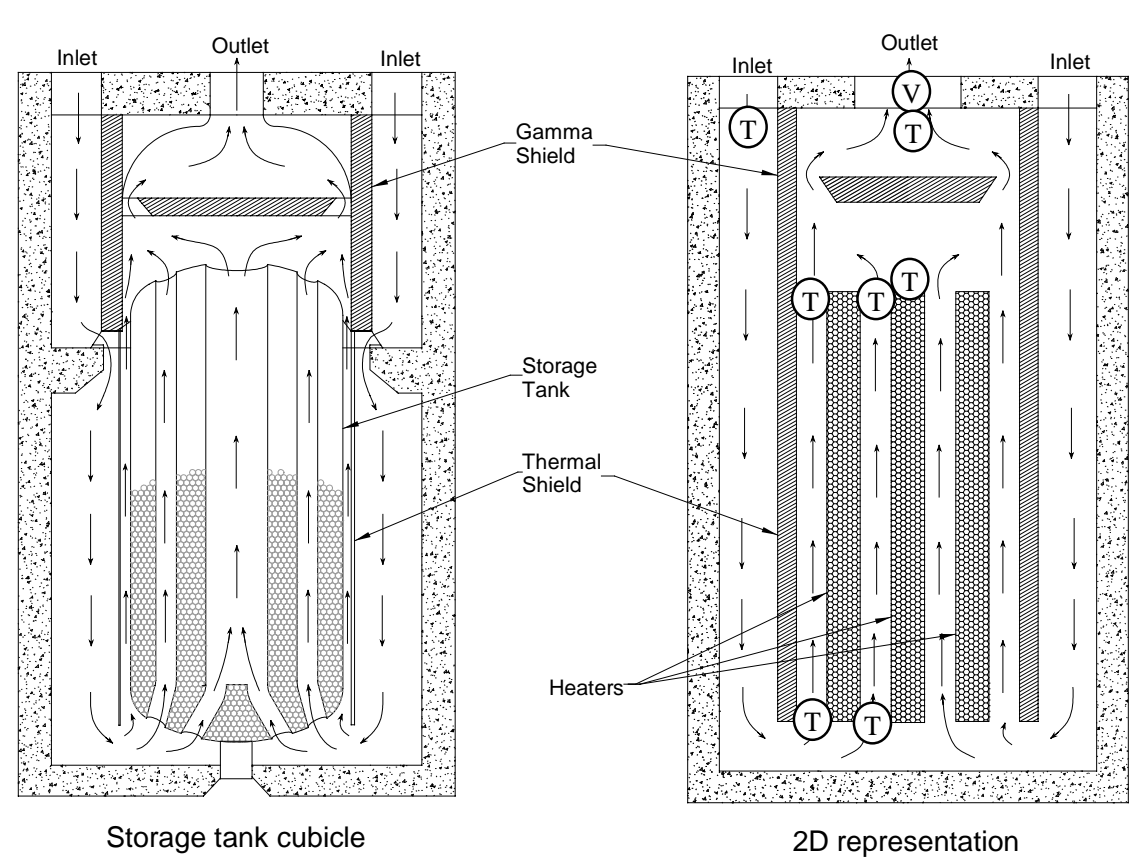

Figure 4. Schematic of the analogy between the storage tank cubicle and the 2D passive cooling demonstrator test setup.

The flow regime in the test was laminar as opposed to the turbulent flow expected for the tank. This implied that the heat transfer coefficients and flow losses were less than for the tank. However, only the resultant mass flow and temperatures were different, not the flow pattern.

In order to visualize the flow effects, temperature sensors were placed at various positions in the air stream as indicated in Figure 4. By looking at the relative temperatures, one could deduct the flow direction. Also, the rate at which the temperature changed gave an indication to the transient response. Additionally, smoke traces were injected at different positions to visualize the flow. Figure 5 shows a sequence of photos as the smoke is introduced in the air stream.

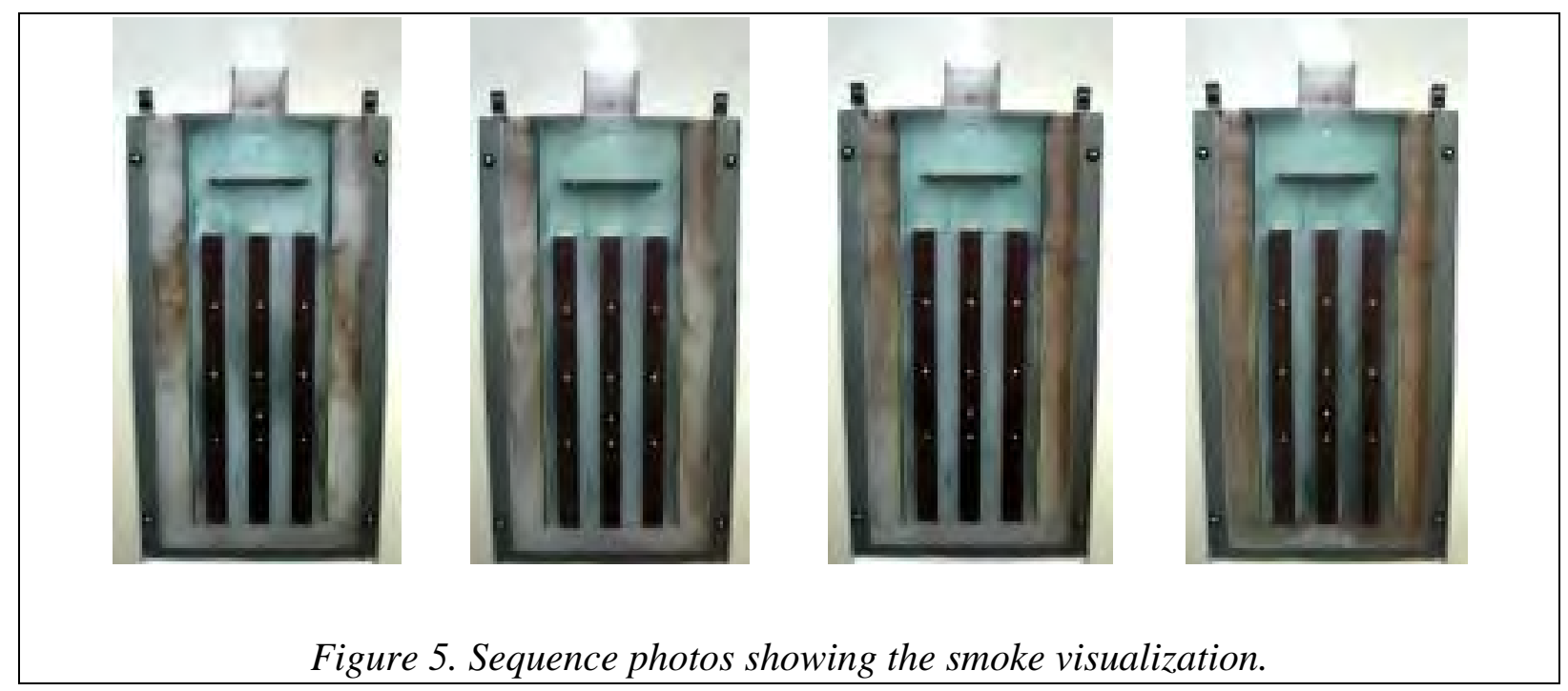




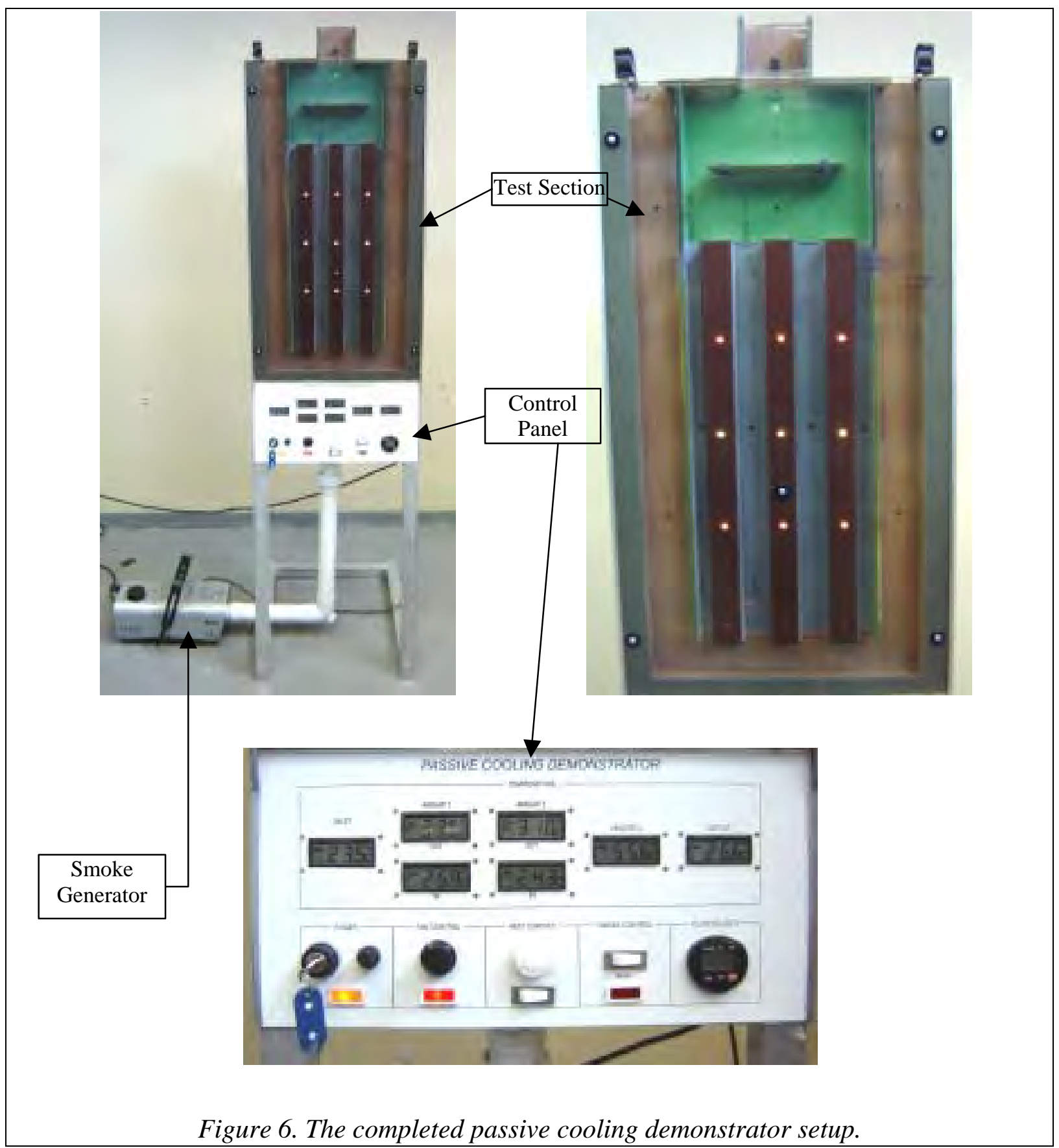

Figure 6 shows the complete test setup. Overall, the test setup was a great success. The temperature probes clearly indicated the direction of airflow, as well as the effect of transients. With the heater at $70^{\circ} \mathrm{C}$, the maximum air temperature reached $40^{\circ} \mathrm{C}$ with an inlet of $25^{\circ} \mathrm{C}$. Flow velocities of about $0.3 \mathrm{~m} / \mathrm{s}$ were measured at the outlet during passive flow. This is quite a significant flow if one considers that there is only a $15^{\circ} \mathrm{C}$ temperature difference that drives the buoyancy flow.

The test was started from cold by switching on only the low fill level heaters. The passive cooling started on its own, and the air moved in the correct direction with no exception. This is a clear demonstration that even at very low heat and fill levels, passive cooling will start in the desired direction. Also, it is not necessary to "start" the flow using a fan, as it can start on its own.

Another test was done where the flow was forced by the fans in the reverse direction through the test. This would represent an unfavorable pressure difference across the building as was simulated with the Flownex model. The flow was kept in reverse for sufficient time that the hottest part of the air was in the gap between the shield and the "concrete". Contrary to what the Flownex analysis showed, the flow immediately stops when the fans 
are switched off and return in the "correct" direction. Within a few seconds the initial passive flow is reestablished.

The smoke helped to show how the air stops and starts to form local circulation zones when the outlets are blocked. During such a case, the air changes direction in the gap of the thermal shield, creating a circulation up through the inner tubes and down through the thermal shield gap. Another circulation zone is established in the gap between the shield and the "concrete" wall. The same phenomenon was also seen in the transient CFD analyses and Flownex. The moment the blockage at the outlet was removed, the flow started again in the desired direction. It took less than three seconds for all the smoke that remained in the test to be vented, i.e. the passive flow starts so quickly that within a few seconds it is back to equilibrium.

\subsection{Summary of results}

The CFD analyses showed that it is possible to cool the tanks passively. Sufficient mass flow is generated to ensure the fuel temperatures are within limits. Even at low fill levels, passive cooling can still exist. By optimizing the chimney and building inlet losses, it is believed that passive cooling will result in mass flows similar to what is required to keep the fuel below $350^{\circ} \mathrm{C}$ under all circumstances.

The technique to calculate the mass flow in and around a tank using the pipe network software Flownex allows one to analyze a large range of active, transient and passive cooling scenarios. By relating the results to tank and fuel results from 3D CFD analyses, one can deduce the actual temperatures. It is also the only feasible way to introduce the flow characteristics of the CCU, since modeling a complete CCU with CFD is just too complex.

The Flownex analysis showed recirculation around the tank in some cases, which were also seen with CFD transient analyses. The time response of the air is so fast that constant tank temperatures can be assumed during the transients.

The passive cooling demonstrator also verified the passive cooling ability of the tanks. It showed similar flow characteristics found by CFD and Flownex. The only difference was that Flownex showed a stable reverse flow condition, but this could not be reproduced with the demonstrator. This may be due to thermal participation of the surrounding structures of the demonstrator, which is not included in the Flownex model. It is planned to verify this with a CFD analysis.

\section{CONCLUSIONS}

Three diverse methods were used to verify the passive cooling ability of the tanks that showed that there is a high confidence that the decay heat can be removed by passive means under all circumstances.

The phenomenon of a stable reverse flow scenario needs to be further investigated. Also, a full-scale test is planned for a single cooling pipe to determine the exact heat transfer coefficients. This will add confidence in the CFD model's prediction of the heat transfer, which eventually determines the maximum fuel temperature.

All passive cooling analyses assume that the inlets and outlets are open. Special attention should thus be given to the protection and availability of the openings. If all openings are blocked, the temperatures will rise at a certain rate. Transient analyses will show the time before material limits are reached. Retention time is seen as the next line of defense if passive cooling cannot be established.

In conclusion, it can be said that as long as the inlets and outlets are open, decay heat removal of the fuel can be achieved through passive means. 